\section{Palladium-Catalyzed Synthesis of Pyrimidine Nucleoside Analogs}

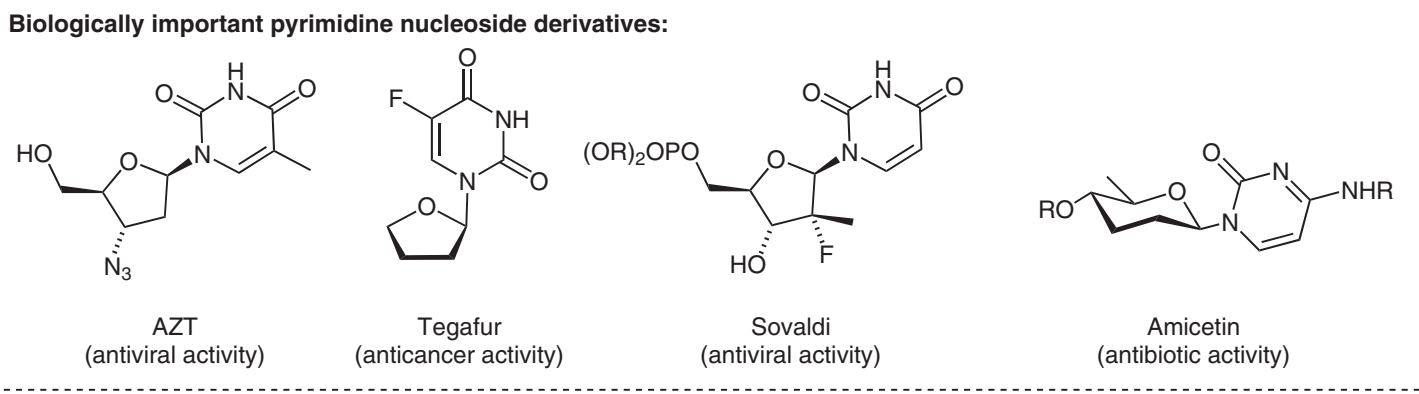

Category

Chemistry in

Medicine and Biology

\section{Key words}

pyrimidine nucleoside analogs

oxygen heterocycles iodoetherification

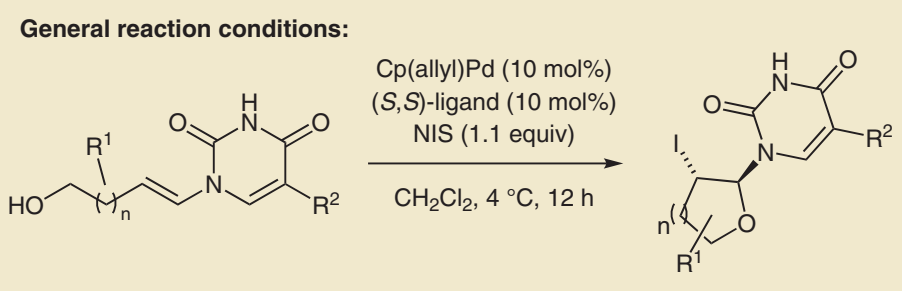

Substrate scope:<smiles>Cc1cn(C2OCCC(=CS(C)(=O)=O)CC2I)c(=O)[nH]c1=O</smiles>

$90 \%$ yield, $90 \%$ ee Derivatization reactions:

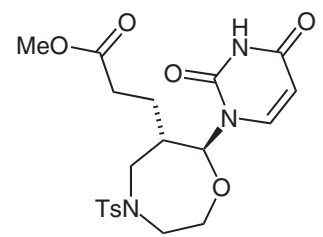<smiles>CS(=O)(=O)/C=C1/CCOC(n2cc(F)c(=O)[nH]c2=O)[C@H](I)C1</smiles>

91\% yield, $91 \%$ ee $\quad 96 \%$ yield, $99 \%$ ee

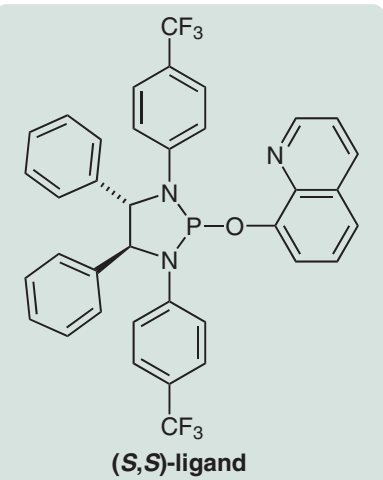

$(S, S)$-ligand
Significance: Many FDA approved antiviral and anticancer drugs contain nucleoside analogs. The biologically active nucleosides are synthesized either by derivatization of an intact nucleoside or by coupling a nitrogenous base with a modified sugar (glycolsylation reaction). However, all previous methods suffered from poor yields and low diastereoselectivities.

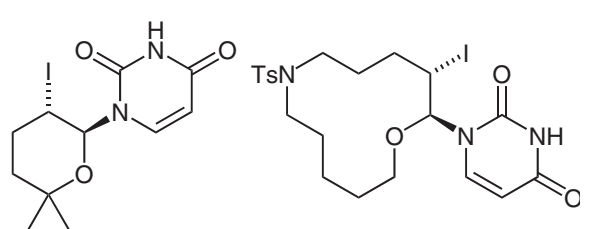

$94 \%$ yield, $99.5 \%$ ee

$84 \%$ yield, $99.5 \%$ ee

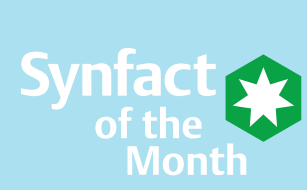

Comment: Trost and co-workers reported a new Pd-catalyzed synthesis of pyrimidine nucleoside analogs bearing an iodide substituent. This process occurs in high yields as well as excellent enantioand diastereoselectivity ( $d r>20: 1)$. The products can be transformed into a variety of new pyrimidine nucleoside analogs. According to the proposed mechanism, the reaction proceeds through a $\mathrm{Pd}(\mathrm{IV})$ species, which undergoes reductive elimination to form a C-I bond. 